\title{
C1 Hemilaminectomy for Resection of Foramen Magnum Meningioma: 2-Dimensional Operative Video
}

\author{
Stefan Lieber ${ }^{1,2}$ Rocio Evangelista-Zamora ${ }^{1} \quad$ Maximiliano Nunez $^{2} \quad$ Marcos Tatagiba $^{1}$ \\ 1 Department of Neurological Surgery, Eberhard-Karls-University, \\ University Hospital Tübingen, Tübingen, Germany \\ 2 Department of Neurological Surgery, Microsurgical Neuroanatomy Lab, \\ University of Pittsburgh, Pittsburgh, Pennsylvania, United States \\ Address for correspondence Stefan Lieber, MD, Department of \\ Neurological Surgery, Eberhard-Karls-University, \\ Hoppe-Seyler-Strasse 3, Tübingen, D-72076, Germany \\ (e-mail: Stefan.Lieber@uclmail.net).
}

J Neurol Surg B 2021;82(suppl S1):S35-S36.

\begin{abstract}
Keywords

- foramen magnum

- C1 hemilaminectomy

- craniocervical junction

- meningioma

- concorde position

- operative video

We present a case of a sizeable foramen magnum meningioma that was resected through a $\mathrm{C} 1$ hemilaminectomy in prone (concorde) position. The patient is a 51-year-old woman with a 3-month history of progressive paresthesia of the upper and lower extremities, followed by gait disturbance, and hand apraxia. There was no complaint of nuchal pain.

On magnetic resonance imaging (MRI) a briskly enhancing extra-axial, intradural craniospinal lesion, extending from the basion of the lower clivus, over the tectorial membrane to the middle of the axis' body was discovered. There was significant transposition and compression of the medulla and corresponding focal hyperintensity on T2-weighted imaging.

On physical examination, the patient was ambulatory independently, notwithstanding a pronounced spinal ataxia. There were deficits in sensation and proprioception, as well as urinary retention, but preserved function of the lower cranial nerves.

In view of the profound transposition of the medulla, utilization of the corridor created by the tumor seemed feasible and we felt that a limited $\mathrm{C} 1$ hemilaminectomy would provide sufficient microsurgical access thus obviating a more extensive and invasive approach to the craniocervical junction.

A gross-total resection was achieved; histopathology confirmed a World Health Organization (WHO) grade I angiomatous meningioma with a low-proliferation index. The patient was discharged home 3 days after surgery and her spinal ataxia resolved completely within 3 months of out-patient rehabilitation. At 3-year follow-up, there was no indication of residual or recurrence.

The link to the video can be found at: https://youtu.be/WyShbfr-xi0.
\end{abstract}

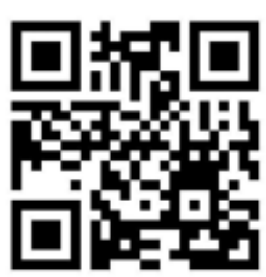

received

May 6, 2019

accepted

September 29, 2019

published online

March 13, 2020

Conflict of Interest

None declared.

www.thieme.com/skullbasevideos

www.thieme.com/jnlsbvideos

DOI https://doi.org/

10.1055/s-0039-3402056.

ISSN 2193-6331. (c) 2020. The Author(s).

This is an open access article published by Thieme under the terms of the Creative Commons Attribution-NonDerivative-NonCommercial-License, permitting copying and reproduction so long as the original work is given appropriate credit. Contents may not be used for commercial purposes, or adapted, remixed, transformed or built upon. (https://creativecommons.org/ licenses/by-nc-nd/4.0/)

Georg Thieme Verlag KG, Rüdigerstraße 14, 70469 Stuttgart, Germany 


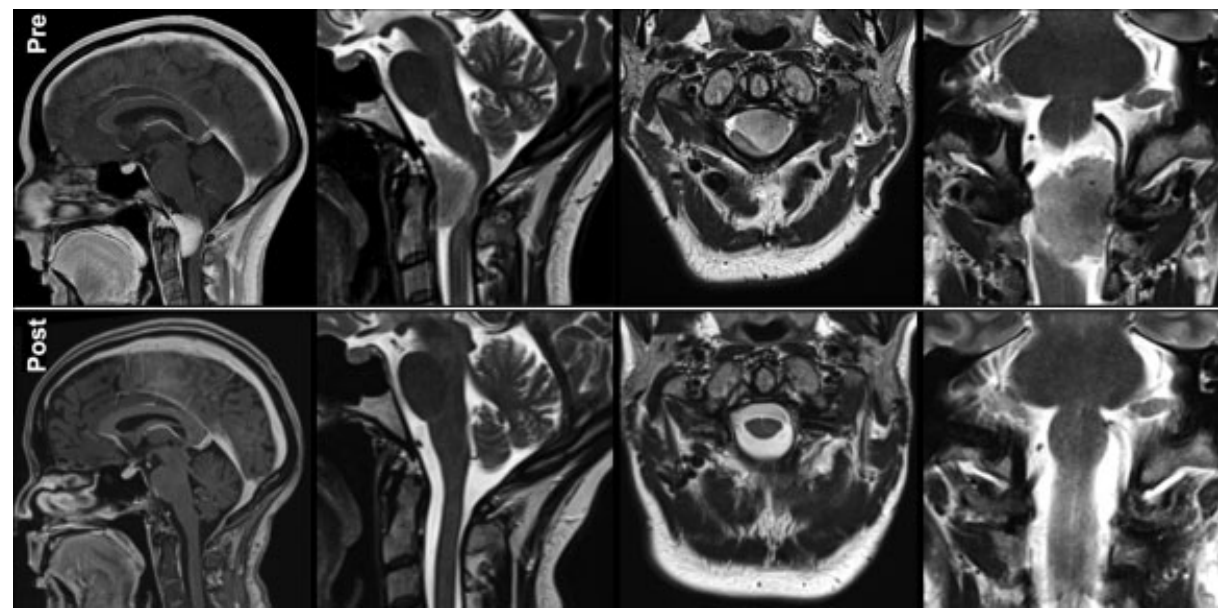

Fig. 1 Pre- and postoperative MRI studies of this intradural craniospinal meningioma that extends from the basion of the lower clivus over the tectorial membrane to the middle of the axis' body. It originates anterolaterally, occupies most of the foramen magnum's space, and profoundly displaces the medulla posteriorly and contralaterally. MRI, magnetic resonance imaging.

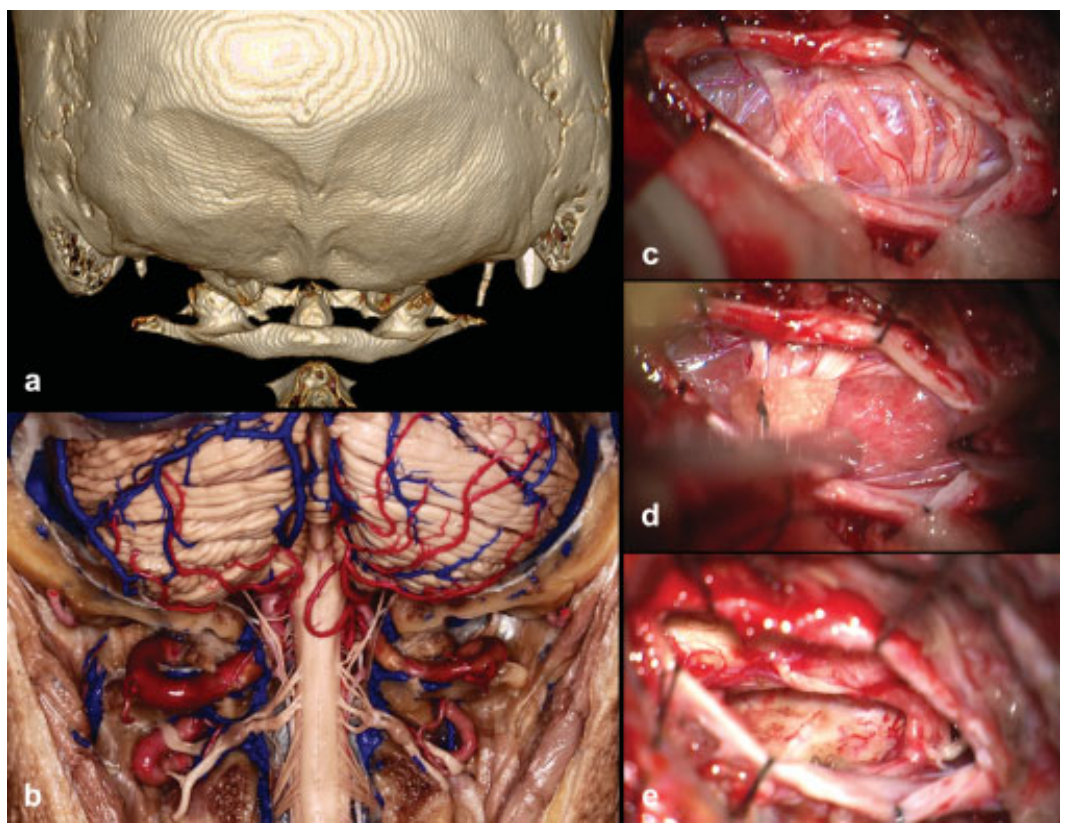

Fig. 2 (A) CT 3D reconstruction (actual patient) of the craniocervical junction, and (B) anatomical dissection (fixed, silicone injected human cadaver) of the correlating intradural neurovascular structures. Operative still images of a left-sided C1 hemilaminectomy: (C) exposure of the anterolateral meningioma, rootlets of the spinal accessory nerve, $C 1$ and $C 2$ are transposed posterolaterally, (D) dissection of the meningioma's capsule via an inferomedial surgical corridor, (E) after complete microsurgical excision and bipolar coagulation of the dural attachment sites on clivus, tectorial membrane, and posterior longitudinal ligament. 3D, three-dimensional; CT, computed tomography.

\section{Comments}

This is a nice video demonstrating resection of a foramen magnum meningioma through a paramedian skin incision and a hemilaminectomy. Performing microdissection between and around the $\mathrm{C} 2$ nerve roots and spinal accessory nerve is shown. This is a nice approach for meningiomas ventral to the spinal cord and minimizes the skin incision and risk of a pseudomeningocele collection postoperatively.
Carl B. Heilman, MD

Tufts Medical Center

Boston, Massachusetts

\section{Disclosures}

None. The authors have no personal, institutional, or financial interest in any of the materials, drugs, or devices described in this article. 